\title{
Parent's Perceived Provision of Information Regarding Diagnosis to Children with Brain Tumors
}

\author{
Iori Sato', Akiko Higuchi',2, Takaaki Yanagisawa3 , Akitake Mukasa4, Kohmei Ida', \\ Yutaka Sawamura6, Kazuhiko Sugiyama ${ }^{7}$, Nobuhito Saito ${ }^{4}$, Toshihiro Kumabe ${ }^{8}$, \\ Mizuhiko Terasaki ${ }^{9}$, Ryo Nishikawa ${ }^{10}$, Yasushi Ishida'11, Kiyoko Kamibeppu ${ }^{1}$ \\ ${ }^{1}$ Department of Family Nursing, Division of Health Sciences and Nursing, Graduate School of Medicine, The \\ University of Tokyo, Tokyo, Japan \\ ${ }^{2}$ Children's Cancer Association of Japan, Tokyo, Japan \\ ${ }^{3}$ Division of Pediatric Neuro-Oncology, Department of Neuro-Oncology/Neurosurgery, Comprehensive Cancer \\ Center, International Medical Center, Saitama Medical University, Hidaka, Japan \\ ${ }^{4}$ Department of Neurosurgery, Faculty of Medicine, The University of Tokyo, Tokyo, Japan \\ ${ }^{5}$ Department of Pediatrics, Teikyo University Mizonokuchi Hospital, Kawasaki, Japan \\ ${ }^{6}$ Sawamura Neurosurgery Clinic, Sapporo, Japan \\ ${ }^{7}$ Department of Clinical Oncology \& Neuro-Oncology Program, Hiroshima University Hospital, Hiroshima, Japan \\ ${ }^{8}$ Department of Neurosurgery, Tohoku University Graduate School of Medicine, Sendai, Japan \\ ${ }^{9}$ Department of Neurosurgery, Kurume University School of Medicine, Kurume, Japan \\ ${ }^{10}$ Department of Neuro-Oncology/Neurosurgery, Comprehensive Cancer Center, International Medical Center, \\ Saitama Medical University, Hidaka, Japan \\ ${ }^{11}$ Pediatric Medical Center, Ehime Prefectural Central Hospital, Matsuyama, Japan \\ Email: kkamibeppu-tky@umin.ac.jp
}

Received 13 April 2015; accepted 10 May 2015; published 13 May 2015

Copyright (C) 2015 by authors and Scientific Research Publishing Inc.

This work is licensed under the Creative Commons Attribution International License (CC BY).

http://creativecommons.org/licenses/by/4.0/

\section{Abstract}

Background: The aim of this study was to clarify the degree of information provision to children with brain tumors, factors influencing this provision, and the relationship between this provision and psychosocial consequences. Methods: A total of 157 parents completed a questionnaire on the degree of information provision to their children and sociodemographic and medical characteristics. Parents and their children completed subscales of the Pediatric Quality of Life Inventory (PedsQL) Cancer Module. Relevant factors were investigated using ordinal logistic regression analysis and compared with PedsQL scores by degree of information provision with adjustment for age. Results: The majority of children aged 2 - 4 years received a low level of information only in regard to medical procedure and preparation. The majority of children aged 5 - 11 years were 
provided information regarding disease symptoms and treatment, but not actual diagnosis. Approximately half of children aged 12 - 18 years were provided detailed information including their actual diagnosis. Older children generally received more information regarding their disease (odds ratio $[0 R]=1.3$ per 1 year old, $P<0.001$ ), while children with intellectual disability received less $(O R=0.2, P=0.006)$. The provision of information did not worsen scores for Procedural Anxiety, Treatment Anxiety, Worry, or Communication. Conclusions: To our knowledge, this is the first report on the degree of information provision to children with brain tumors. Parents of children with brain tumors in Japan provide information dependent on age and intellectual level. The disclosure of information to children regarding their disease might affect their trust of medical and health care professionals.

\section{Keywords}

\section{Adolescent, Brain Neoplasms, Child, Quality of Life, Truth Disclosure}

\section{Introduction}

With 5-year survival rates among pediatric brain tumor patients approaching 75\% [1], physicians now face the challenge of enhancing psychosocial outcomes. Both children undergoing treatment for brain tumors and survivors require information regarding their diagnosis, treatment, follow-up care, and late effects [2] [3]. Continuous and honest communication is important to help these children build trusting relationships with medical professionals and participate in treatment and health management [4] [5]. The first step in facilitating this open communication is ensuring that medical professionals and parents provide children with accurate and appropriate information regarding their diagnosis [6].

Although several studies in the past 30 years have discussed the degree of information that should be provided to children with life-threatening diseases [3] [6]-[9], several factors must be considered for those with brain tumors. First, when children are diagnosed with a brain tumor, they might appear unable to comprehend detailed information due to symptoms such as headache, neurological dysfunction, and cognitive impairment [10]. Second, as several types of brain tumors are associated with high mortality [11], information might be withheld out of concern for the child's psychological well-being. In fact, a marked proportion of pediatric oncologists (14.4\%) reported that they only revealed the diagnosis to children with a good prognosis [8]. Third, children with brain tumors showed more procedural and treatment anxiety than those with other types of cancer [12]. Children with brain tumors might receive limited information regarding their disease and therefore experience a higher degree of anxiety.

In a Japanese study conducted in parents of children with hematological and solid cancer in the 1990s, the majority of mothers (53/57) concealed the diagnosis to prevent their child from experiencing stress [13]. The remaining mothers $(4 / 57)$ revealed the diagnosis to provide peace of mind (e.g. before stem cell transplantation [SCT]) [13]. Parents' will must be considered when informing children of their diagnosis [8] [14]. Useful references for parents deciding to disclose or conceal their child's diagnosis are the proportion of informed children, conditions for which a higher or lower level of information is provided, and whether informed children are more anxious or reassured than uninformed children. To provide further references for parents, we developed a study protocol based on the hypotheses that 1) children with brain tumors are provided information on their disease based on age and intellectual level; 2) a high proportion of information regarding diagnosis is provided to children treated at specific institutions, with a good prognosis, receiving specific treatment, and whose parents are without anxiety/depression; and 3) informed children are not more anxious, worried, or incommunicative than uninformed children.

Here, we clarified the degree of information provision to children with brain tumors regarding their diagnosis, factors relevant to this provision, and the relationship between this provision and psychosocial outcomes.

\section{Methods}

This study was conducted in combination with the development of the Japanese version of the PedsQL Brain 
Tumor Module [15]. We used the data to focus on how parents perceive the provision of information regarding diagnosis to their children.

\subsection{Study Population and Procedure}

Children with brain tumors and their parents were recruited from six hospitals across Japan and the Children's Cancer Association of Japan (CCAJ) from September to December 2008. Inclusion criteria were children aged 2 - 18 years who were diagnosed at least 1 month prior to study initiation.

Researchers presented this study verbally and in writing to 122 parents at participating hospitals, and an invitation to a meeting on brain tumors and notice to participate in this study were sent concurrently to all families by the CCAJ. A total of 120 parents recruited from hospitals and 52 contacted by the CCAJ agreed to participate $(\mathrm{n}=172)$.

Researchers also presented this study to 101 children of the 120 parents recruited from hospitals (19 too young to respond [2 - 4 years]) and 46 children of the 52 parents from the CCAJ (6 too young to respond [2 - 4 years]). Of these 147 children, 143 agreed to participate with assistance from their parents. Questionnaires were distributed to 172 parents and 143 children.

Questionnaires were returned by 167 parents and 138 children. We excluded questionnaires from 10 parents who did not select 1 of the 4 levels of information provision (described below) and candidate factors related to these 4 levels of information provision (sociodemographic, disease, and treatment variables noted in the latter section). Answers from 157 parents and 130 children were analyzed.

\subsection{Ethical Considerations}

This study was approved by the review boards of all seven participating institutions. As only a proportion of children had been informed of their diagnosis, the terms "cancer" or "tumor" were avoided and terms such as "your disease" were instead used with children in introductory literature and questionnaires. Children aged 12 years or older and all parents provided written consent prior to participation. Children younger than 12 years provided informed verbal assent.

\subsection{Measurements}

The degree of information provision to children was collected from parents. Children were not asked how or what they were informed of regarding their disease to prevent mistrust of parents or medical professionals. Parents were asked to choose from the following options regarding the degree of information they and medical professionals provided: 1) little information, 2) moderate information regarding disease, 3) detailed information regarding disease, including diagnosis (disease name) or 4) other degree of information. Of these options, no parents selected 4). Parents were allowed some free description of the degree of information they provided to their children.

To confirm whether the degree of information provided was related to potential psychosocial outcomes for children, we measured aspects of health-related quality of life in children using four subscales (Procedural Anxiety [3 items], Treatment Anxiety [3 items], Worry [3 items], and Communication [3 items]) of the Pediatric Quality of Life Inventory (PedsQL) Cancer Module [16] [17]. Children were asked to describe the extent to which each item troubled them in the previous month. Example items of each scale were "I get scared about needle sticks" (Procedural Anxiety), "I get scared when I am waiting to see the doctor" (Treatment Anxiety), "I worry that my disease will come back or relapse" (Worry), and "It is hard for me to tell the doctors and nurses how I feel” (Communication). For children aged 8 - 18 years, a 5-point Likert response scale was used $(0=$ never a problem; 1 = almost never; 2 = sometimes; 3 = often; $4=$ almost always). For children aged $5-7$ years, a 3-point face scale was used. Items were reverse-scored and linearly transformed to a 0 - 100 scale, with higher scores indicating better HRQOL (lower anxiety or better communication). To account for missing data, scale scores were computed as the sum of items divided by number of items answered. If more than $50 \%$ of items were missing or incomplete, the score was not computed. Cronbach's alpha coefficients [18] of these subscales were reported as 0.77 to 0.88 [18]. To complement the interpretation of results, parents were also asked to determine their child's HRQOL using the PedsQL. Cronbach's alpha coefficients of the parent reports ranged from 0.86 to 0.96 [18]. 
Parents were questioned regarding their child's sociodemographic status and medical history to determine any relation to information provision, as follows: gender, age, tumor pathology, age at diagnosis and presence or absence of intellectual disability (perceived by parents), and previous instances of neurosurgery, radiotherapy, chemotherapy, or SCT. Parents were also questioned regarding their level of academic achievement and psychological distress. Psychological distress was measured by the Kessler-10 (K10) questionnaire [19] [20], with higher scores indicating higher psychological distress in relation to depression or anxiety. If the score could not be computed because of missing or incomplete items, sample mean score was assigned for subsequent analysis as described below. Cronbach's alpha coefficient was reported as 0.92 [21]. Children aged 8 years or older were questioned regarding their level of trait anxiety, which was measured by the State-Trait Anxiety Inventory for Children (STAIC) questionnaire [22] [23]. A higher score indicated a higher predisposition to anxiety. Cronbach’s alpha coefficient was 0.89 [15].

\subsection{Statistical Analysis}

Statistics were calculated using IBM SPSS software, version 19 (SPSS, Inc., Chicago, IL, USA) and R version 2.13.1 (R Foundation for Statistical Computing, Vienna, Austria) [24]. Level of significance was defined as 0.05. Participant characteristics were represented as sociodemographic and medical histories of children and sociodemographic background and psychological distress of parents. The degree of information provision to children with brain tumors was categorized by age.

Ordinal logistic regression was performed with the degree of information provision as a dependent variable. The 13 independent variable candidates were: child's age at recruitment, age at diagnosis, gender, recruited institution, type of brain tumor, treatment status, reported intellectual disability and experienced neurosurgery, chemotherapy, radiation, and SCT, as well as parent's education level and K10 score. The independent variables were selected via the best-subset selection procedure, where the results of ordinal logistic regression with every combination of independent variable candidates $\left(2^{13}-1\right.$ results) were sorted in ascending order of Akaike's information criterion (AIC). Regression models with lower AIC values were optimal [25] [26], and the top five (lowest AIC values) were shown. A similar analysis with 14 independent variables including STAIC scores was conducted for parents and children aged 8 years or older.

Child-reported PedsQL scores were calculated with respect to the degree of information provided to each child. To clarify the relationship between information provision and psychosocial outcomes, analysis of variance (ANOVA), trend test, and analysis of covariance (ANCOVA) for adjustment by age were performed. Correlation coefficients between information provision and psychosocial outcomes were calculated with regard to childand parent-reported outcomes to compare differences between the two.

\section{Results}

\subsection{Participant Characteristics}

Median age of children with brain tumors was 10.0 years (range: 2 - 18), and the sample was heterogeneous for tumor pathology (Table 1). Most children presented with embryonal tumors, low-grade gliomas, and germ cell tumors. Median age at diagnosis was 6.0 years. Of the 157 parents questioned, 62 (39.5\%) answered that their children were still receiving treatment and 95 (60.5\%) that their children had completed treatment. The interval from completion of treatment to the survey ranged from 0.1 - 13.3 years. Twelve parents (7.6\%) perceived their child as intellectually disabled. The majority of parents questioned were mothers (91.7\%), and median age of the parents was 40.0 years (range: 23 - 63).

\subsection{Degree of Information Provision to Children with Brain Tumors}

The majority of parents of children aged 2 - 4 years (15/24, 63\%) provided a low level of information (Table 2). As a case example, one parent who answered "they provided little information" further explained the necessity for oral medication and injection for their 4-year-old son with craniopharyngioma. Another parent explained the implementation of tumorectomy for their 6-year-old daughter with optic glioma, who had been diagnosed and receiving chemotherapy since 2 years of age.

The majority of parents of children aged 5 - 11 years (42/70, 60\%) provided a moderate level of information. One parent who answered that they "provided a moderate level of information about their disease," referred to 
Table 1. Participant characteristics $(\mathrm{n}=157)$.

\begin{tabular}{|c|c|c|c|c|c|}
\hline & $\mathbf{n}$ & $\%$ & Mean & Median & SD \\
\hline Age of children at survey (years) & 157 & & 9.9 & 10.0 & 4.4 \\
\hline $2-4$ & 24 & 42.1 & & & \\
\hline $5-7$ & 29 & 18.5 & & & \\
\hline $8-12$ & 54 & 34.4 & & & \\
\hline $13-18$ & 50 & 31.8 & & & \\
\hline \multicolumn{6}{|l|}{ Gender } \\
\hline Male & 88 & 56.1 & & & \\
\hline Female & 69 & 43.9 & & & \\
\hline \multicolumn{6}{|l|}{ Tumor pathology } \\
\hline Embryonal tumors & 46 & 29.3 & & & \\
\hline Germ cell tumors & 36 & 22.9 & & & \\
\hline Low-grade gliomas & 38 & 24.2 & & & \\
\hline High-grade gliomas & 23 & 14.6 & & & \\
\hline Other & 14 & 8.9 & & & \\
\hline Age at diagnosis (years) & 157 & & 6.4 & 6.0 & 4.5 \\
\hline Time from diagnosis (months) & 157 & & 41.5 & 32.0 & 39.5 \\
\hline \multicolumn{6}{|l|}{ Treatment status } \\
\hline On treatment & 62 & 39.5 & & & \\
\hline Off treatment & 95 & 60.5 & & & \\
\hline \multicolumn{6}{|c|}{ Current intellectual disability (perceived by parents) } \\
\hline Presence & 12 & 7.6 & & & \\
\hline Absence & 145 & 92.4 & & & \\
\hline \multicolumn{6}{|l|}{ Neurosurgery } \\
\hline Received & 143 & 91.1 & & & \\
\hline Never received & 14 & 8.9 & & & \\
\hline \multicolumn{6}{|l|}{ Radiotherapy } \\
\hline Received & 108 & 68.8 & & & \\
\hline Never received & 49 & 31.2 & & & \\
\hline \multicolumn{6}{|l|}{ Chemotherapy } \\
\hline Received & 118 & 75.2 & & & \\
\hline Never received & 39 & 24.8 & & & \\
\hline \multicolumn{6}{|l|}{ Stem cell transplantation } \\
\hline Received & 17 & 10.8 & & & \\
\hline Never received & 140 & 89.2 & & & \\
\hline Trait anxiety of children ${ }^{a, b}$ & 94 & & 34.8 & 35.5 & 8.7 \\
\hline \multicolumn{6}{|l|}{ Relationship to child } \\
\hline Mother & 144 & 91.7 & & & \\
\hline Father & 10 & 6.4 & & & \\
\hline Grandmother & 2 & 1.3 & & & \\
\hline Grandfather & 1 & 0.6 & & & \\
\hline Age of parents at survey (years) ${ }^{a}$ & 156 & & 39.9 & 40.0 & 6.3 \\
\hline \multicolumn{6}{|l|}{ Academic achievement of parent } \\
\hline High school & 64 & 40.8 & & & \\
\hline College or university & 93 & 59.2 & & & \\
\hline Parent's psychological distress ${ }^{\mathrm{a}, \mathrm{c}}$ & 155 & & 8.1 & 6.0 & 7.3 \\
\hline
\end{tabular}

SD, standard deviation; ${ }^{a}$ Missing data excluded; ${ }^{b}$ Trait anxiety subscale scores of the State-Trait Anxiety Inventory for Children (range 20 - 60); higher score indicate higher trait anxiety of children aged 8 or older; 'Kessler-10 scores (range 10 - 50); higher score indicates higher psychological distress of parents. 
Table 2. Degree of information provision to children with brain tumors $(n=157)$.

\begin{tabular}{|c|c|c|c|c|c|c|c|}
\hline & \multirow{2}{*}{$\begin{array}{c}\text { Total } \\
157 \\
\end{array}$} & \multicolumn{2}{|c|}{$\begin{array}{l}\text { (1) Little information } \\
n(\%)\end{array}$} & \multicolumn{2}{|c|}{$\begin{array}{c}\text { (2) Moderate information } \\
\text { n (\%) }\end{array}$} & \multicolumn{2}{|c|}{$\begin{array}{c}\text { (3) Detailed information } \\
\text { n (\%) }\end{array}$} \\
\hline & & 33 & (21.0) & 73 & $(46.5)$ & 51 & (32.5) \\
\hline \multicolumn{8}{|c|}{ Age (years) } \\
\hline 2 & 3 & 2 & (66.7) & 1 & (33.3) & 0 & $(0.0)$ \\
\hline 3 & 8 & 7 & (87.5) & 1 & (12.5) & 0 & $(0.0)$ \\
\hline 4 & 13 & 6 & $(46.2)$ & 5 & (38.5) & 2 & (15.4) \\
\hline 5 & 5 & 1 & (20.0) & 3 & $(60.0)$ & 1 & (20.0) \\
\hline 6 & 14 & 4 & (28.6) & 8 & (57.1) & 2 & (14.3) \\
\hline 7 & 10 & 4 & $(40.0)$ & 5 & (50.0) & 1 & (10.0) \\
\hline 8 & 12 & 3 & (25.0) & 7 & (58.3) & 2 & (16.7) \\
\hline 9 & 7 & 1 & (14.3) & 5 & (71.4) & 1 & (14.3) \\
\hline 10 & 12 & 0 & $(0.0)$ & 7 & (58.3) & 5 & (41.7) \\
\hline 11 & 10 & 1 & $(10.0)$ & 7 & (70.0) & 2 & (20.0) \\
\hline 12 & 13 & 2 & (15.4) & 4 & (30.8) & 7 & (53.8) \\
\hline 13 & 16 & 1 & (6.3) & 8 & (50.0) & 7 & $(43.8)$ \\
\hline 14 & 7 & 1 & (14.3) & 3 & (42.9) & 3 & (42.9) \\
\hline 15 & 9 & 0 & $(0.0)$ & 3 & (33.3) & 6 & (66.7) \\
\hline 16 & 5 & 0 & $(0.0)$ & 1 & $(20.0)$ & 4 & $(80.0)$ \\
\hline 17 & 8 & 0 & $(0.0)$ & 2 & $(25.0)$ & 6 & (75.0) \\
\hline 18 & 5 & 0 & $(0.0)$ & 3 & $(60.0)$ & 2 & $(40.0)$ \\
\hline
\end{tabular}

Most frequent responses by age emphasized.

the disease as "a boil in the head" and not as "brain tumor" to their 12-year-old son with a mixed germ cell tumor who had been diagnosed and underwent a tumorectomy, whole-brain irradiation, and chemotherapy at 8 years of age.

Of the 63 parents of children aged 12 - 18 years, 35 provided detailed information including diagnosis (disease name), 24 provided a moderate level of information, and 4 provided little information. All parents of children aged over 15 years provided at least a moderate level of information. One parent who answered that they "provided information in detail about children's disease, including diagnosis (disease name)" further explained using the term "brain tumor" and "cancer" for their 12-year-old daughter with medulloblastoma, who had been diagnosed and underwent a tumorectomy, local radiation, and chemotherapy at 1 year of age. The parent also clarified that they did not provide information regarding the late effects of disease, symptoms and treatment regarding childhood cancer.

\subsection{Factors Relevant to Degree of Information Provision}

Due to the large number of results obtained in the best-subset procedure, only the top five models (lowest AIC) are shown (Table 3). Parents of older children were more likely (odds ratio [OR] $=1.3$ per year of age) to provideinformation regarding disease than those of younger children, and parents of children with intellectual disability (perceived by parents) were less likely to provide information $(\mathrm{OR}=0.2)$ than those without. Parents of children who had undergone specific treatment, particularly SCT $(\mathrm{OR}=2)$, appeared more likely to provide information, but not to a statistically significant degree. Parents with anxiety/depression appeared less likely to provide information ( $\mathrm{OR}=0.98$ per 1 -point increase in $\mathrm{K} 10$ score), but also not to a statistically significant 
Table 3. Odds related to degree of information provision for children with brain tumors $(\mathrm{n}=157)$.

\begin{tabular}{|c|c|c|c|c|c|}
\hline \multirow{2}{*}{ Independent variable } & Model 1 & Model 2 & Model 3 & Model 4 & Model 5 \\
\hline & $\begin{array}{c}\text { OR } \\
\mathrm{P}\end{array}$ & $\begin{array}{c}\text { OR } \\
\mathrm{P}\end{array}$ & $\begin{array}{c}\text { OR } \\
\mathrm{P}\end{array}$ & $\begin{array}{c}\text { OR } \\
P\end{array}$ & $\begin{array}{c}\text { OR } \\
\mathrm{P}\end{array}$ \\
\hline Age of children at recruitment (per year of age) & $\begin{array}{c}1.30 \\
<0.001\end{array}$ & $\begin{array}{c}1.30 \\
<0.001\end{array}$ & $\begin{array}{c}1.29 \\
<0.001\end{array}$ & $\begin{array}{c}1.29 \\
<0.001\end{array}$ & $\begin{array}{c}1.30 \\
<0.001\end{array}$ \\
\hline Reported intellectual disability & $\begin{array}{c}0.15 \\
0.006\end{array}$ & $\begin{array}{c}0.19 \\
0.013\end{array}$ & $\begin{array}{c}0.18 \\
0.011\end{array}$ & $\begin{array}{c}0.16 \\
0.008\end{array}$ & $\begin{array}{c}0.15 \\
0.006\end{array}$ \\
\hline Experienced stem cell transplantation & $\begin{array}{c}2.3 \\
0.136\end{array}$ & - & - & $\begin{array}{c}2.2 \\
0.152\end{array}$ & $\begin{array}{c}2.1 \\
0.162\end{array}$ \\
\hline Experienced neurosurgery & - & - & $\begin{array}{c}1.8 \\
0.321\end{array}$ & - & $\begin{array}{c}1.6 \\
0.393\end{array}$ \\
\hline K10 score of parents (per 1 point) & - & - & - & $\begin{array}{c}0.98 \\
0.384\end{array}$ & - \\
\hline Nagelkerke $\mathrm{R}^{2}$ & 0.352 & 0.341 & 0.347 & 0.352 & 0.356 \\
\hline AIC & 281.35 & 281.56 & 282.53 & 282.59 & 282.60 \\
\hline
\end{tabular}

AIC, Akaike’s information criterion; K10, Kessler-10; OR, odds ratio Ordinal logistic regression implemented. Dependent variables were degree of information provided regarding disease $(1=$ little information, 2 = moderate level of information regarding clinical condition and treatment, and 3 = detailed level of information regarding clinical condition and treatment, including disease name); independent variable candidates were child's age at recruitment, age at diagnosis, gender, recruited institution, type of brain tumor, treatment status, reported mental retardation, experienced neurosurgery, experienced chemotherapy, experienced radiation, and experienced stem cell transplantation, and education and K10 score of parent; independent variables were selected via best-subset selection procedure based on AIC. This table presents the top 5 (lowest AIC) models.

degree. The best-subset procedure did not select other factors such as child's age at diagnosis, gender, recruited institution, type of brain tumor, treatment status, experienced chemotherapy, experienced radiation, or parent's education as influential factors on information disclosure within the top five models (Table 3). Regarding trait anxiety among children aged 8 years or older, STAIC scores were not associated with the degree of information in every model.

\subsection{Degree of Information Provision and Psychosocial Outcomes}

The degree of information provision was not significantly related to scores for Procedural Anxiety, Worry, or Communication (Table 4). In spite of non-significant statistically, children provided detailed information including diagnosis reported pretty higher scores for Procedural Anxiety than those provided moderate or little information (79.8 versus 70.7 and 68.6), indicating less anxiety for medical procedure, needle stick, and blood sampling. Similarly, the more informed children reported higher scores for Communication; however, this trend was attenuated when the covariate effect of age was adjusted.

The degree of information provision significantly related to Treatment Anxiety. The more-informed children reported higher scores for Treatment Anxiety than less-informed children, indicating less anxiety for treatment, being in the hospital, and interacting with physicians. This trend remained even when the covariate effect of age was adjusted. Correlation analysis also indicated that the more-informed children reported higher scores for Treatment Anxiety than less-informed children ( $r=0.20$ - 0.30) (Table 5).

Similar trends were observed for parent-reports of the PedsQL; the signs of correlation coefficients between information provision and psychosocial outcomes reported by parents were identical with those reported by children. However, the correlation between the degrees of information provision and psychosocial outcomes reported by parents were smaller than those reported by children and not statistically significant (Table 5).

\section{Discussion}

Here, we report the degree of information provision to children with brain tumors in Japan and describe factors influencing this provision. Age and intellectual disability were the only factors relevant to the degree of information provision. Informed children did not appear more anxious, worried, or incommunicative than uninformed children. Quite the contrary, more-informed children showed a higher degree of treatment reassurance.

To our knowledge, this is the first report on the degree of information provision to children with brain tumors. 
Table 4. Psychosocial outcomes reported from children with brain tumor aged 5 - 18 years by degree of information provision $(\mathrm{n}=130)$.

\begin{tabular}{|c|c|c|c|c|c|}
\hline $\begin{array}{l}\text { PedsQL scale score by } \\
\text { degree of information }\end{array}$ & $\mathbf{n}$ & Mean & SD & $\mathbf{P}(\mathbf{A A})$ & $P$ for trend (AA) \\
\hline \multicolumn{6}{|l|}{ Procedural anxiety } \\
\hline Little information & 17 & 68.6 & 38.9 & 0.255 & 0.123 \\
\hline Moderate information & 62 & 70.7 & 32.7 & $(0.656)$ & $(0.580)$ \\
\hline Detailed information & 45 & 79.8 & 25.2 & & \\
\hline \multicolumn{6}{|l|}{ Treatment anxiety } \\
\hline Little information & 17 & 81.9 & 29.5 & 0.007 & 0.003 \\
\hline Moderate information & 62 & 90.6 & 21.3 & $(0.085)$ & $(0.030)$ \\
\hline Detailed information & 46 & 98.2 & 5.5 & & \\
\hline \multicolumn{6}{|l|}{ Worry } \\
\hline Little information & 16 & 86.5 & 21.5 & 0.379 & 0.750 \\
\hline Moderate information & 62 & 79.0 & 26.5 & $(0.360)$ & $(0.895)$ \\
\hline Detailed information & 45 & 84.3 & 19.8 & & \\
\hline \multicolumn{6}{|l|}{ Communication } \\
\hline Little information & 17 & 56.9 & 40.5 & 0.023 & 0.021 \\
\hline Moderate information & 63 & 63.2 & 30.5 & $(0.201)$ & $(0.145)$ \\
\hline Detailed information & 45 & 77.0 & 25.3 & & \\
\hline
\end{tabular}

AA, P-value with analysis of covariance (ANCOVA) adjusted by age (“age-adjusted”); PedsQL, Pediatric Quality of Life Inventory; SD, standard deviation; Higher scores indicate higher quality of life (lower anxiety or more communication). Example items of each scale were "I get scared about having needle sticks" (Procedural Anxiety), "I get scared when I am waiting to see the doctor" (Treatment Anxiety), "I worry that my disease will come back or relapse" (Worry), and "It is hard for me to tell the doctors and nurses how I feel” (Communication). Missing data were excluded.

Parents of children aged 5 years or older provided at least a moderate level of information regarding their disease. The main reason for non-disclosure of disease by parents was concern of shocking children psychologically [14]. Our results might be used as a reference when deciding to disclose or conceal information to their children, particularly those concerned about their child being too young to cope with such information.

The majority of parents of children aged 4 years or younger provided a low level of information regarding their disease. Based on free descriptions, most information provided appeared to regard concrete and visible procedures, out of consideration for potential fear and anxiety the child might experience. Parents explained their intentions, particularly in cases where they might require their child's cooperation or when their child was hurt. However, the majority of parents did not intend to explain the diagnosis to their child. Although more information, including disease name, was provided as age increased, there was no defined cutoff age at which certain information was deemed acceptable to disclose. Even for high-school students, approximately half did not know the name ("brain tumor") of their disease. Parents often avoided providing accurate information about their child's disease, instead explaining in an easy-to-understand manner (e.g. "a boil in the head").

This unspoken policy of secrecy regarding disease is more common in Japan than the UK and USA [9] [27]. For example, in the USA, during the 1990s the majority (75\%) of parents of young children with cancer (mean age, 5.45 years [SD 1.00]) reported that their children were aware of their diagnosis [7]. In contrast, in Japan, during the 1990s the majority of (64\%) pediatric oncologists had never revealed the diagnosis to their patients [8]. Several studies have since clarified that the pattern of information provision differs between cultures [9] [28]-[30]. Similar to Japan, populations in several countries and areas such as Korea [31], China [32], Taiwan [33], Iran [30], and Italy [34] exhibited similar trends regarding the level of information on cancer diagnosis provided to "fragile" patients. The free descriptions from parents in this study demonstrate one way of talking to children about their disease in an appropriate manner. 
Table 5. Relationship of perceived degree of information provision by parents to psychosocial outcomes of children with brain tumors aged $5-18$ years $(n=130)$.

\begin{tabular}{|c|c|c|c|}
\hline & \multicolumn{2}{|c|}{$\begin{array}{l}\text { Perceived degree of information provision by parents and } \\
\text { psychosocial outcomes by children or parents }\end{array}$} & \multirow{2}{*}{$\begin{array}{l}\text { Correlation between } \\
\text { child- and } \\
\text { parent-reported scores }\end{array}$} \\
\hline & Reported by children & Reported by parents & \\
\hline \multicolumn{4}{|l|}{ Procedural Anxiety } \\
\hline Correlation coefficient & 0.17 & 0.14 & 0.69 \\
\hline (P-value) & $(0.058)$ & $(0.122)$ & \\
\hline Age-adjusted (AA) & 0.07 & 0.07 & 0.68 \\
\hline (P-value) & $(0.399)$ & $(0.438)$ & \\
\hline Corrected for attenuation (CA) & 0.17 & 0.15 & 0.75 \\
\hline AA and CA & 0.08 & 0.08 & 0.74 \\
\hline \multicolumn{4}{|l|}{ Treatment Anxiety } \\
\hline Correlation coefficient & 0.28 & 0.17 & 0.45 \\
\hline (P-value) & $(0.002)$ & $(0.057)$ & \\
\hline Age-adjusted (AA) & 0.20 & 0.11 & 0.43 \\
\hline (P-value) & $(0.025)$ & $(0.232)$ & \\
\hline Corrected for attenuation (CA) & 0.30 & 0.17 & 0.50 \\
\hline AA and CA & 0.21 & 0.11 & 0.47 \\
\hline \multicolumn{4}{|l|}{ Worry } \\
\hline Correlation coefficient & 0.17 & -0.09 & 0.27 \\
\hline (P-value) & $(0.851)$ & $(0.257)$ & \\
\hline Age-adjusted (AA) & 0.03 & -0.05 & 0.27 \\
\hline (P-value) & $(0.751)$ & $(0.578)$ & \\
\hline Corrected for attenuation (CA) & 0.02 & -0.11 & 0.34 \\
\hline AA and CA & 0.03 & -0.05 & 0.34 \\
\hline \multicolumn{4}{|l|}{ Communication } \\
\hline Correlation coefficient & 0.24 & 0.17 & 0.52 \\
\hline (P-value) & $(0.007)$ & $(0.046)$ & \\
\hline Age-adjusted (AA) & 0.16 & 0.13 & 0.51 \\
\hline (P-value) & $(0.082)$ & $(0.139)$ & \\
\hline Corrected for attenuation (CA) & 0.27 & 0.18 & 0.63 \\
\hline AA and CA & 0.18 & 0.14 & 0.62 \\
\hline
\end{tabular}

AA, partial correlation adjusted by age of child; CA, correlation coefficient corrected for attenuation.

Our findings describe the current degree of information provision to children with brain tumors in Japan. In principle, children must be provided all information regarding their disease with consideration for their age and developmental level [5] [35] [36]. In addition, to encourage the provision of information to children with brain tumors, cultural background should be considered.

The age and intellectual disability of children were identified as factors relevant to the degree of information provision, findings consistent with a previous study showing that age was associated with disclosure of diagnosis to children with HIV/AIDS [37]. Other factors, such as child's gender and socioeconomic status, were se- 
lected in the predictive model but were not significantly associated with disclosure, unlike the previous study [37]. In the present study, specific treatments (SCT and neurosurgery) increased information provision to children and were selected as considerable factors using the best-subset procedure. However, the influence of specific treatment on information provision was minor. Throughout the course of treatment, parents and physicians had consultations regarding information provision to their child. These findings indicate the consistent attitude of parents and physicians regarding the provision of information irrespective of tumor type and treatment course. Of course in clinical practice, the degree of information provision is decided case-by-case [8]. On age bracket stratification, children aged 12 years or older appeared to have been informed about their diagnosis more often on a case-by-case basis than younger children. There might also be instances of case-by-case decisions beyond the studied factors. For example, unstudied factors such as the requests of children might influence the degree of information provision.

Disclosure of a cancer diagnosis to children varies between hospitals [27], and parents' will regarding disclosure is affected by that of the physician [13] [14]. We therefore found it surprising that the recruited institutions (six hospitals and one association) were located in different regions yet had no effect on information provision. The recruited hospitals are considered the location where children received their treatment, even for children currently receiving no treatment, as most pediatric brain tumor survivors in Japan receive follow-up at the same hospital continuously, for an average of 15 years after diagnosis [38]. Further, the CCAJ is the largest organization supporting children with cancer and their families and provides various means of support to members (parents), including counseling on how to inform children of their disease [39]. These facts suggest that each recruiting institution conducted the best possible practice for information provision and open communication to children with brain tumors. We requested that this study be conducted with leading physicians of treatment for pediatric brain tumors. The findings of this study might therefore reflect a higher level of information provision to children than other institutions in Japan.

Here, we confirmed that informed children are not more anxious, worried, or incommunicative than uninformed children, a finding consistent with adult cancer patients in China [40]. Further, informed children were less anxious about treatment, hospitals, and physicians than uninformed children. The disclosure to children of information regarding their disease appears to contribute to their trust of medical and health care professionals. To our knowledge, this is the first empirical evidence of a relationship between information provision to children with cancer and psychosocial outcomes. This finding might help parents communicate their child's diagnosis to provide them both peace of mind.

The reverse relationship between information provision to children and anxiety requires discussion, as less information might have been provided to children perceived as anxious. However, two results of the present study support a directional relationship between information provision and anxiety of children. First, this study measured trait anxiety, which is a stable characteristic of children [22] [23], and confirmed that trait anxiety was not related to the degree of information provision. This finding therefore suggests that parents determining the level of information to provide to children based on their trait anxiety is unlikely. Second, we confirmed that the relationship between information provision to children and their self-reported anxiety was clearer than that between information provision to children and parent-reported anxiety of children. If parents were indeed determining the level of information they should provide to a child based on the child's level of anxiety, then perceived anxiety of children should be more related to provision of information than child-reported anxiety; however, this was not the case. Therefore, a directional relationship between information provision and psychosocial outcomes of children might exist, rather than reverse relationship.

Although ethically speaking diagnosis information should be provided to children, obtaining empirical evidence on outcomes of such information provision is difficult, as controlled intervention studies are unethical. While a proportion of previous cross-sectional observational studies in adult cancer patients noted relationships between information provision to patients and their health outcomes [40], the possibility of a reverse relationship (relationships between patients' health outcomes to the degree of information provision) could not be discounted. We therefore consider the parent-child paired data to be a methodological strength of the present study that enables the acquisition of strong evidence regarding the effect of information provision on the psychosocial outcomes of children, despite this being a cross-sectional study.

Provision of information by parents might influence psychosocial outcomes of children pleiotropically. When parents provide information regarding diagnosis to their child, the psychosocial outcomes of the child might be improved due to the acquirement of new knowledge of themselves, confidence in the ability to manage their 
physical and psychosocial complaints, or relief by being informed. Furthermore, of note, the relationship between parents' provision of information and children's psychosocial outcomes is not necessarily mediated by children's understanding or recall of such information. If, even after receiving information regarding their diagnosis, children do not understand (or forget) the information, their psychosocial outcomes may still be improved due to parents' relief in having explained the situation to the child, heightened family functioning due to parents' peace of mind, or parents and medical staff being more honest and open and therefore in a better position to care for children. While the present study somewhat clarified the pleiotropic influence of provision of information perceived by parents on the psychosocial outcomes of children, further research is required to clarify the process and mechanism by which this influence is enacted.

Several other limitations to the present study warrant mention. First, our ability to generalize the data is limited. While the response rate at hospitals was high, rates at the CCAJ are unknown, as several hundred families were notified of this study through the CCAJ, including those not eligible to participate. Parents might not have enrolled to prevent their children from any possible negative psychosocial outcomes due to participation in this study. Further, the findings of this study might reflect a higher level of information provision to children under the best possible practice than that in other institutions in Japan.

Second, our results should be interpreted with caution, as this was a cross-sectional study conducted at one time point. When children were informed of their diagnosis and how they experience current psychosocial outcomes after information provision remains unknown. We also measured the psychological distress of parents using the K10 score, which only indicates their current condition. Past mental conditions or medical history of parents could influence their desire to provide information to children regarding their disease.

Third, our results should also be interpreted with caution, as the degree of information was determined according to simple and subjective questions. Parents were only questioned regarding the diagnosis (disease name) and condition of their child, and information provided in the present study does not include the prognosis of the disease. In addition, what was considered "little information" by some parents may have been considered "moderate information" by others. However, these questions could be considered effective indicators of information provision in context, as statistically significant results were obtained even when the question had some degree of error and no parents selected the fourth response (instead providing other degrees of information). The question and response choices in the present study matched those of parents in a clinical setting in Japan [41], where an important step is that children were provided information regarding disease condition (difference between the first and second response) and regarding disease name (difference between the second and third response.

Fourth, we did not conduct an a priori sample size calculation because the present study was conducted in parallel with a related study that has a predetermined sample size [15]. This study indicated that the influence of disease and treatment factors on information provision was minor, if present at all. A larger sample might clarify additional relationships between relevant factors and information provision. Specific treatments and the anxiety or depression of parents can be considered, among others.

In the future, a qualitative study should be conducted to explore types of practice implemented in leading hospitals and analyze how this can be applied to other hospitals. How information is provided (by parents, by physicians, by nurses, or by them role sharing) is also important. A more detailed survey should then be conducted to clarify the contents of "provided a moderate level of information," which would be useful for parents and medical professionals when explaining the disease and treatment to children with brain tumors.

\section{Conclusion}

Here we report the degree of information provision to children with brain tumors in Japan in 2008. Parents of children with brain tumors provided information dependent on the child's age and intellectual level. Children aged 5 years or older received information on a moderate or detailed level regarding their disease. Regarding ethnical/cultural considerations, children should not uniformly receive information regarding their diagnosis. The provision of information did not make children more anxious, worried, or incommunicative. This study provides evidence that information provision to children regarding their disease is the first step in fostering open communication with medical professionals.

\section{Acknowledgements}

This study was supported by a Grant-in-Aid for Pediatric Cancer Treatment and Research from the CCAJ 2008 
and a Grant-in-Aid for Cancer Research from the Ministry of Health, Labour and Welfare of Japan (No. 18-14) 2008.

\section{References}

[1] Siegel, R., Naishadham, D. and Jemal, A. (2013) Cancer Statistics, 2013. CA: Cancer Journal of Clinicians, 63, 11-30. http://dx.doi.org/10.3322/caac.21166

[2] Freeman, K., O’Dell, C. and Meola, C. (2003) Childhood Brain Tumors: Children’s and Siblings' Concerns Regarding the Diagnosis and Phase of Illness. Journal of Pediatric Oncology Nursing, 20, 133-140. http://dx.doi.org/10.1053/jpon.2003.74

[3] Gianinazzi, M.E., Essig, S., Rueegg, C.S., von der Weid, N.X., Brazzola, P., Kuehni, C.E. and Michel, G., For the Swiss Paediatric Oncology Group (2014) Information Provision and Information Needs in Adult Survivors of Childhood Cancer. Pediatric Blood and Cancer, 61, 312-318. http://dx.doi.org/10.1002/pbc.24762

[4] Mack, J.W. and Grier, H.E. (2004) The Day One Talk. Journal of Clinical Oncology, 22, 563-566. http://dx.doi.org/10.1200/JCO.2004.04.078

[5] Masera, G., Chesler, M.A., Jankovic, M., Ablin, A.R., Ben Arush, M.W., Breatnach, F., McDowell, H.P., Eden, T., Epelman, C., Bellani, F.F., Green, D.M., Kosmidis, H.V., Nesbit, M.E., Wandzura, C., Wilbur, J.R. and Spinetta, J.J. (1997) SIOP Working Committee on Psychosocial Issues in Pediatric Oncology: Guidelines for Communication of the Diagnosis. Medical and Pediatric Oncology, 28, 382-385. http://dx.doi.org/10.1002/(SICI)1096-911X(199705)28:5<382::AID-MPO12>3.0.CO;2-D

[6] Uys, R. (2010) Communication in the Diagnosis of Childhood Cancer. Continuing Medical Education, 28, $347-348$.

[7] Hardy, M.S., Armstrong, F.D., Routh, D.K., Albrecht, J. and Davis, J. (1994) Coping and Communication among Parents and Children with Human Immunodeficiency Virus and Cancer. Journal of Developmental and Behavioral Pediatrics, 15, S49-S54. http://dx.doi.org/10.1097/00004703-199406001-00009

[8] Kaneko, Y. and Matsushita, T. (1995) Revealing a True Diagnosis, Informed Consent, and Palliative Care in Cancer Children-A Questionnaire to Japanese Pediatric Oncologists. The Journal of the Japan Pediatric Society, 99, 534539.

[9] Parsons, S.K., Saiki-Craighill, S., Mayer, D.K., Sullivan, A.M., Jeruss, S., Terrin, N., Tighiouart, H., Nakagawa, K., Iwata, Y., Hara, J., Grier, H.E. and Block, S. (2007) Telling Children and Adolescents about Their Cancer Diagnosis: Cross-Cultural Comparisons between Pediatric Oncologists in the US and Japan. Psycho-Oncology, 16, 60-68. http://dx.doi.org/10.1002/pon.1048

[10] Reulecke, B.C., Erker, C.G., Fiedler, B.J., Niederstadt, T.U. and Kurlemann, G. (2008) Brain Tumors in Children: Initial Symptoms and Their Influence on the Time Span between Symptom Onset and Diagnosis. Journal of Child Neurology, 23, 178-183. http://dx.doi.org/10.1177/0883073807308692

[11] Hargrave, D., Bartels, U. and Bouffet, E. (2006) Diffuse Brainstem Glioma in Children: Critical Review of Clinical Trials. The Lancet Oncology, 7, 241-248. http://dx.doi.org/10.1016/S1470-2045(06)70615-5

[12] Sato, I., Higuchi, A., Yanagisawa, T., Mukasa, A., Ida, K., Sawamura, Y., Sugiyama, K., Saito, N., Kumabe, T., Terasaki, M., Nishikawa, R., Ishida, Y. and Kamibeppu, K. (2014) Cancer-Specific Health-Related Quality of Life in Children with Brain Tumors. Quality of Life Research, 23, 1059-1068. http://dx.doi.org/10.1007/s11136-013-0555-X

[13] Saiki-Craighill, S. (1999) The Trajectory of the Battle: The Development of the Mother When a Child Is Lost to Cancer. Kawashima Shoten, Tokyo, 46-48.

[14] Saiki-Craighill, S. (1999) The Trajectory of the Battle: The Development of the Mother When a Child is Lost to Cancer. Kawashima Shoten, Tokyo, 54.

[15] Sato, I., Higuchi, A., Yanagisawa, T., Mukasa, A., Ida, K., Sawamura, Y., Sugiyama, K., Saito, N., Kumabe, T., Terasaki, M., Nishikawa, R., Ishida, Y. and Kamibeppu, K. (2010) Development of the Japanese Version of the Pediatric Quality of Life Inventory Brain Tumor Module. Health and Quality of Life Outcomes, 8, 38. http://dx.doi.org/10.1186/1477-7525-8-38

[16] Varni, J.W., Burwinkle, T.M., Katz, E.R., Meeske, K. and Dickinson, P. (2002) The PedsQL in Pediatric Cancer: Reliability and Validity of the Pediatric Quality of Life Inventory Generic Core Scales, Multidimensional Fatigue Scale, and Cancer Module. Cancer, 94, 2090-2106. http://dx.doi.org/10.1002/cncr.10428

[17] Tsuji, N., Kakee, N., Ishida, Y., Asami, K., Tabuchi, K., Nakadate, H., Iwai, T., Maeda, M., Okamura, J., Kazama, T., Terao, Y., Ohyama, W., Yuza, Y., Kaneko, T., Manabe, A., Kobayashi, K., Kamibeppu, K. and Matsushima, E. (2011) Validation of the Japanese Version of the Pediatric Quality of Life Inventory (PedsQL) Cancer Module. Health and Quality of Life Outcomes, 9, 22. http://dx.doi.org/10.1186/1477-7525-9-22

[18] Cronbach, L.J. (1951) Coefficient Alpha and the Internal Structure of Tests. Psychometrika, 16, 297-334. 
http://dx.doi.org/10.1007/BF02310555

[19] Furukawa, T.A., Kawakami, N., Saitoh, M., Ono, Y., Nakane, Y., Nakamura, Y., Tachimori, H., Iwata, N., Uda, H., Nakane, H., Watanabe, M., Naganuma, Y., Hata, Y., Kobayashi, M., Miyake, Y., Takeshima, T. and Kikkawa, T. (2008) The Performance of the Japanese Version of the K6 and K10 in the World Mental Health Survey Japan. International Journal of Methods in Psychiatric Research, 17, 152-158. http://dx.doi.org/10.1002/mpr.257

[20] Furukawa, T.A., Kessler, R.C., Slade, T. and Andrews, G. (2003) The Performance of the K6 and K10 Screening Scales for Psychological Distress in the Australian National Survey of Mental Health and Well-Being. Psychological Medicine, 33, 357-362. http://dx.doi.org/10.1017/S0033291702006700

[21] Sato, I., Higuchi, A., Yanagisawa, T., Mukasa, A., Ida, K., Sawamura, Y., Sugiyama, K., Saito, N., Kumabe, T., Terasaki, M., Nishikawa, R., Ishida, Y. and Kamibeppu, K. (2013) Factors Influencing Self- and Parent-Reporting HealthRelated Quality of Life in Children with Brain Tumors. Quality of Life Research, 22, 185-201. http://dx.doi.org/10.1007/s11136-012-0137-3

[22] Spielberger, C.D., Edward, C.D., Lushene, R.E., Montouri, J. and Platzek, D. (1973) STAIC Preliminary Manual for the State-Trait Anxiety Inventory for Children ("How I Feel Questionnaire”). Consulting Psychological Press Inc., California.

[23] Soga, S. (1983) A Study on Standardization of Japanese Version of the STAIC. Japanese Journal of Psychology, 54, 215-221. http://dx.doi.org/10.4992/jipsy.54.215

[24] R Development Core Team (2011) R: A Language and Environment for Statistical Computing. R Foundation for Statistical Computing, Vienna. http://www.R-project.org/

[25] de Leeuw, J. (1992) Introduction to Akaike (1973) Information Theory and an Extension of the Maximum Likelihood Principle. In: Kotz, S. and Johnson, N.L., Eds., Breakthroughs in Statistics, Vol. 1. Foundations and Basic Theory. Springer Series in Statistics, Perspectives in Statistics, Springer-Verlag, New York, 599-609.

[26] Akaike, H. (1992) Information Theory and an Extension of the Maximum Likelihood Principle. In: Kotz, S. and Johnson, N.L., Eds., Breakthroughs in Statistics, Vol. 1. Foundations and Basic Theory. Springer Series in Statistics, Perspectives in Statistics, Springer-Verlag, New York, 610-624. http://dx.doi.org/10.1007/978-1-4612-0919-5 38

[27] Watanabe, A., Nunes, T. and de Abreu, G. (2014) Japanese Parents' Perception of Disclosing the Diagnosis of Cancer to Their Children. Clinical Child Psychology and Psychiatry, 19, 125-138. http://dx.doi.org/10.1177/1359104512470599

[28] Trill, M.D. and Kovalcik, R. (1997) The Child with Cancer. Influence of Culture on Truth-Telling and Patient Care. Annals of the New York Academy of Sciences, 809, 197-210. http://dx.doi.org/10.1111/j.1749-6632.1997.tb48083.x

[29] Ishibashi, A. (1996) Four Concepts That Distinguish Pediatric Oncology Care in Japan from That in the United States: Telling the Diagnosis, Length of Hospitalization, Home Care, and Support Systems. Journal of Pediatric Oncology Nursing, 13, 226-231. http://dx.doi.org/10.1177/104345429601300408

[30] Zahedi, F. (2011) The Challenge of Truth Telling across Cultures: A Case Study. Journal of Medical Ethics and History of Medicine, 4, 11.

[31] Blackhall, L.J., Murphy, S.T., Frank, G., Michel, V. and Azen, S. (1995) Ethnicity and Attitudes toward Patient Autonomy. JAMA: The Journal of the American Medical Association, 274, 820-825. http://dx.doi.org/10.1001/jama.1995.03530100060035

[32] Wong, M.Y.F. and Chan, S.W.C. (2006) The Qualitative Experience of Chinese Parents with Children Diagnosed of Cancer. Journal of Clinical Nursing, 15, 710-717. http://dx.doi.org/10.1111/j.1365-2702.2006.01297.x

[33] Arraras, J.I., Greimel, E., Chie, W.C., Sezer, O., Bergenmar, M., Costantini, A., Young, T., Vlasic, K.K., Velikova, G. and European Organisation for Research and Treatment of Cancer Quality of Life Group (2013) Cross-Cultural Differences in Information Disclosure Evaluated Through the EORTC Questionnaires. Psycho-Oncology, 22, $268-275$.

[34] Grassi, L., Giraldi, T., Messina, E.G., Magnani, K., Valle, E. and Cartei, G. (2000) Physicians’ Attitudes to and Problems with Truth-Telling to Cancer Patients. Supportive Care in Cancer, 8, 40-45.

[35] European Association for Children in Hospital (1988) The EACH Charter. http://www.each-for-sick-children.org/each-charter.html

[36] Kunin, H. (1997) Ethical Issues in Pediatric Life-Threatening Illness: Dilemmas of Consent, Assent, and Communication. Ethics\& Behavior, 7, 43-57. http://dx.doi.org/10.1207/s15327019eb0701_4

[37] Wiener, L.S., Battles, H.B., Heilman, N., Sigelman, C.K. and Pizzo, P.A. (1996) Factors Associated with Disclosure of Diagnosis to Children with HIV/AIDS. Pediatric AIDS and HIV Infection, 7, 310-324.

[38] Ishida, Y., Ozono, S., Maeda, N., Okamura, J., Asami, K., Iwai, T., Kamibeppu, K., Sakamoto, N., Kakee, N. and Horibe, K. (2011) Medical Visits of Childhood Cancer Survivors in Japan: A Cross-Sectional Survey. Pediatrics International, 53, 291-299. http://dx.doi.org/10.1111/j.1442-200X.2010.03293.X 
[39] Children’s Cancer Association of Japan (1968). http://www.ccaj-found.or.jp/

[40] Wang, D.C., Guo, C.B., Peng, X. and Su, Y.J. (2014) Psychological Morbidity and Health-Related Quality of Life in Patients with Differing Awareness of Cancer Diagnosis: A Cross-Sectional Study. Psycho-Oncology, 23, 975-980. http://dx.doi.org/10.1002/pon.3512

[41] Nonaka, J. and Asada, M. (2013) Support for Children and Their Family at a Time of Explanation regarding Diagnosis and Treatment. In: Uchida, M., Ed., Nursing Care Guidelines for Children with Cancer and Their Families 2012, Japanese Society of Pediatric Oncology Nursing, Nagano, 14-20. 